\title{
Genetic and functional association of FAM5C with myocardial infarction
}

\author{
Jessica J Connelly ${ }^{1}$, Svati H Shah ${ }^{1,2}$, Jennifer F Doss ${ }^{1}$, Shera Gadson ${ }^{1}$, \\ Sarah Nelson ${ }^{1}$, David R Crosslin ${ }^{1}$, A Brent Hale ${ }^{1}$, Xuemei Lou${ }^{1}$, Ty Wang1, \\ Carol Haynes ${ }^{1}$, David Seo ${ }^{3}$, David C Crossman ${ }^{4}$, Vincent Mooser ${ }^{5}$, \\ Christopher B Granger ${ }^{2}$, Christopher JH Jones ${ }^{6}$, William E Kraus ${ }^{1,2}$, \\ Elizabeth R Hauser ${ }^{1}$ and Simon G Gregory*1
}

\begin{abstract}
Address: ${ }^{1}$ Department of Medicine and Center for Human Genetics, Duke University Medical Center, Durham, NC, USA, ${ }^{2}$ Department of Medicine and Division of Cardiology, Duke University Medical Center, Durham, NC, USA, ${ }^{3}$ Miller School of Medicine, University of Miami, Miami, FL, USA, ${ }^{4}$ University of Sheffield, Sheffield, UK, ${ }^{5}$ GlaxoSmithKline, Philadelphia, PA, USA and ${ }^{6}$ University of Wales College of Medicine, Cardiff, UK

Email: Jessica J Connelly - jessica.connelly@duke.edu; Svati H Shah - shah0029@chg.duhs.duke.edu; Jennifer F Doss - jdoss@chg.duhs.duke.edu; Shera Gadson - sdgadson@chg.duhs.duke.edu; Sarah Nelson - nelso075@chg.duhs.duke.edu; David R Crosslin - cross026@chg.duhs.duke.edu; A Brent Hale - bhale@chg.duhs.duke.edu; Xuemei Lou - xl4@chg.duhs.duke.edu; Ty Wang - wang0077@chg.duhs.duke.edu; Carol Haynes - carol@chg.duhs.duke.edu; David Seo - dseo@med.miami.edu; David C Crossman - d.c.crossman@sheffield.ac.uk; Vincent Mooser - Vincent.2.Mooser@gsk.com; Christopher B Granger - grang001@dcri.duke.edu; Christopher JH Jones - Dr.CJones@bromor-tr.wales.nhs.uk; William E Kraus - william.kraus@duke.edu; Elizabeth R Hauser - hause006@chg.duhs.duke.edu; Simon G Gregory* - simon.gregory@duke.edu * Corresponding author
\end{abstract}

Published: 22 April 2008

BMC Medical Genetics 2008, 9:33 doi:10.1 186/147/-2350-9-33

This article is available from: http://www.biomedcentral.com/I47I-2350/9/33

(c) 2008 Connelly et al; licensee BioMed Central Ltd.

This is an Open Access article distributed under the terms of the Creative Commons Attribution License (http://creativecommons.org/licenses/by/2.0), which permits unrestricted use, distribution, and reproduction in any medium, provided the original work is properly cited.
Received: 24 January 2008 Accepted: 22 April 2008

which permits unrestricted use, distribution, and reproduction in any medium, provided the original work is properly cited.

\begin{abstract}
Background: We previously identified a $40 \mathrm{Mb}$ region of linkage on chromosome Iq in our early onset coronary artery disease (CAD) genome-wide linkage scan (GENECARD) with modest evidence for linkage $(n=420$, LOD 0.95$)$. When the data are stratified by acute coronary syndrome (ACS), this modest maximum in the overall group became a well-defined LOD peak (maximum LOD of 2.17, DISI589/DIS5I8). This peak overlaps a recently identified inflammatory biomarker (MCP-I) linkage region from the Framingham Heart Study (maximum LOD of 4.27, DISI 589) and a region of linkage to metabolic syndrome from the IRAS study (maximum LOD of 2.59, DISI589/ DIS518). The overlap of genetic screens in independent data sets provides evidence for the existence of a gene or genes for CAD in this region.
\end{abstract}

Methods: A peak-wide association screen (457 SNPs) was conducted of a region I LOD score down from the peak marker (168-198 Mb) in a linkage peak for acute coronary syndrome (ACS) on chromosome I, within a family-based early onset coronary artery disease (CAD) sample (GENECARD).

Results: Polymorphisms were identified within the 'family with sequence similarity 5, member $C^{\prime}$ gene (FAM5C) that show genetic linkage to and are associated with myocardial infarction (MI) in GENECARD. The association was confirmed in an independent CAD case-control sample (CATHGEN) and strong association with $\mathrm{MI}$ was identified with single nucleotide polymorphisms (SNPs) in the 3' end of FAM5C. FAM5C genotypes were also correlated with expression of the gene 
in human aorta. Expression levels of FAM5C decreased with increasing passage of proliferating aortic smooth muscle cells (SMC) suggesting a role for this molecule in smooth muscle cell proliferation and senescence.

Conclusion: These data implicate FAM5C alleles in the risk of myocardial infarction and suggest further functional studies of FAM5C are required to identify the gene's contribution to atherosclerosis.

\section{Background}

Coronary artery disease (CAD), and its extreme manifestation of myocardial infarction (MI), is the leading cause of death in the United States [1] and, concomitant with the epidemic of obesity and diabetes is rapidly becoming the leading cause of death in many developing countries [2]. The genetic predilection of CAD has been well-established; family history has been repeatedly shown to be a independent risk factor even after adjustment for shared environmental factors $[3,4]$. The heritability of CAD is particularly strong in early-onset forms of the disease (< 50 years of age) where the relative risk of developing earlyonset CAD in the first-degree sibling is between 3.8 and 12.1 , depending on the age-of-onset in the proband [5].

Myocardial infarction, a serious manifestation of CAD, has also been the subject of genetic analysis. In fact, the only major successes in mapping genes for common, complex cardiovascular disease have focused on the MI phenotype, suggesting that this extreme (but common) manifestation of CAD may be most powerful for disease gene identification. For example, investigators in Iceland carried out a genome wide linkage scan for MI in an Icelandic cohort [6]. Using fine-mapping techniques, the arachidonate 5 -lipoxygenase-activating protein ( $A L O X 5 A P$ ) gene was identified as the major susceptibility gene for MI on chromosome 13q. Although initial results implicated a single gene, expanded analysis of other leukotriene pathway genes identified additional CAD/MI susceptibility genes [7]. Another study of MI revealed evidence for linkage to chromosome 1p34 [8] and later identified apolipoprotein E receptor 2 (LRP8) as an underlying susceptibility gene for familial and premature CAD and MI [9]. Most recently, four CAD/MI genome wide association studies (GWAS) [10-13] concomitantly identified genetic association of a region on chromosome 9p21.3 adjacent to the cyclin-dependent kinase inhibitor 2A (CDKN2A) and cyclin-dependent kinase inhibitor 2B (CDKN2B) genes within independent $\mathrm{MI}$ and CAD populations. A study by Broadbent et al. validated these findings and identified the antisense noncoding RNA in the INK4 locus (ANRIL) as the potential disease-causing gene in this region [14]. Despite these successes, these risk variants in combination do not account for the entire underlying genetic component of MI risk, suggesting further studies to identify additional genetic risk factors are necessary.
We previously identified a 40 megabase region of linkage on chromosome 1q25-31 in 420 families from our early onset CAD genome-wide linkage scan (GENECARD) [15], showing modest evidence for linkage $(n=420$ families, LOD 0.95). A priori stratification by sibling pairs concordant for acute coronary syndrome (ACS; an extreme manifestation of CAD primarily composed of $\mathrm{MI}$ ) revealed that this modest maximum in the overall group became a welldefined linkage peak $(n=228$ families, LOD 2.17, at peak microsatellite marker D1S1589/D1S518). This peak coincides exactly with a quantitative trait locus (QTL) for inflammatory biomarker (monocyte chemoattractant protein 1, MCP-1) linkage in the Framingham Heart Study (LOD 4.27, at peak marker D1S1589) [16], as well as a linkage peak to metabolic syndrome (MetS) from the IRAS family study (LOD 2.59, at peak marker D1S1589/ D1S518) [17]. MCP-1 is a potent inflammatory molecule that promotes monocyte/macrophage accumulation in atherosclerotic plaques, which can lead to plaque instability through chronic inflammation and smooth muscle cell proliferation [18]. Metabolic syndrome is a known strong risk factor for development of CAD and MI [19-21]. The overlap of genetic screens in independent data sets provides strong evidence for the existence of a susceptibility gene or genes for CAD in this region.

We conducted a peak-wide association screen of 457 SNPs across the region one LOD score down from the peak marker (168-198 Mb) on chromosome 1q and identified polymorphisms within the 'family with sequence similarity 5, member C' (FAM5C) gene that show genetic linkage to and are associated with MI. We confirmed association within an independent CAD case-control dataset (CATHGEN) [22,23] and have identified strong association between SNPs within the 3' end of FAM5C and myocardial infarction. We show that FAM5C expression is correlated with FAM5C genotype in human aortas, suggesting that genetically heritable levels of this molecule in the cells that make up the aorta may play a role in atherosclerosis. Importantly, FAM5C is known to promote proliferation, migration, and invasion of pituitary tumors[24], a phenotype relevant to the cellular changes of smooth muscle cells that are associated with the formation and vulnerability of an atherosclerotic plaque $[25,26]$. We identified FAM5C expression in proliferating aortic smooth muscle cells (AoSMCs) and show that levels of 
this molecule decrease with increasing passage, suggesting that FAM5C levels may play a similar role in SMCs as in pituitary cell tumors. We hypothesize that polymorphisms within this gene may alter FAM5C levels in smooth muscle cells, enhancing the atherosclerotic smooth muscle cell phenotype, thus leading to plaque instability and changes in MCP-1 levels.

\section{Methods}

\section{Early-onset CAD family-based sample (GENECARD)}

GENECARD is a collaborative study involving six international investigative sites that make up the GENECARD Study Network. The study is coordinated at Duke University. All study participants signed a consent form approved by the responsible institutional review board or local ethics committee. The study design has been previously reported [27]. Briefly, the initial genome-wide linkage screen within the GENECARD study was composed of 493 affected sibling pairs in 420 families, where at least two siblings met the criteria for early-onset CAD (eoCAD) [15]. In order to obtain a more genetically homogenous sample, using a priori defined analyses, our eoCAD sample was stratified into acute coronary syndrome (ACS) families. The presence of ACS was defined as diagnosis of myocardial infarction or unstable angina in at least two affected siblings (228 families) [15]. ACS is a serious manifestation of CAD which includes the subgroup of MI, and is diagnosed by the presence of at least two of the following three signs/symptoms: chest pain typical of CAD, changes on electrocardiogram, and/or positive serum biomarkers for myocardial infarction (MI). Of the 985 affected individuals in the study, 697 met ACS criteria, with 71 individuals with unstable angina only $(89 \%$ with MI). Given these data, and since MI and ACS represent similar clinical phenotypes, for simplicity we consider the ACS phenotype as primarily a myocardial infarction phenotype. In order to increase the power to detect association in this sample, we included additional individuals from the selected ACS families that were sampled after the initial linkage screen was completed. A total of eight additional parents and 28 additional unaffected siblings were added to the 228 ACS families. Furthermore, two additional families qualified for the ACS phenotype since the original screen and were also included in the analysis. The characteristics of the eoCAD $(n=420)$ and ACS $(n=230)$ GENECARD families are summarized in Table 1.

\section{MI case-control sample (CATHGEN)}

CATHGEN participants were recruited sequentially through the cardiac catheterization laboratories at Duke University Hospital (Durham, North Carolina, United States) with approval from the Duke Institutional Review Board. All participants undergoing catheterization were offered participation in the study and signed informed consent. Medical history and clinical data were collected and stored in the Duke Information System for Cardiovascular Care database maintained at the Duke Clinical Research Institute [28]. Controls and cases were chosen on the basis of extent of CAD as measured by the CAD index (CADi). CADi is a numerical summary of coronary angiographic data that incorporates the extent and anatomical distribution of coronary disease [29]. CADi has

Table I: Clinical characteristics of samples used in this study

\begin{tabular}{|c|c|c|c|c|c|}
\hline Variable & $\begin{array}{l}\text { eoCAD Probands } \\
(n=422)\end{array}$ & $\begin{array}{c}\text { ACS Probands } \\
(n=228)\end{array}$ & $\begin{array}{l}\text { MI Cases } \\
(n=368)\end{array}$ & $\begin{array}{l}\text { Controls } \\
(n=289)\end{array}$ & $\begin{array}{l}\text { Aorta Samples } \\
\quad(n=88)\end{array}$ \\
\hline Age of onset (SD) & $44.2(5.8)$ & $43.9(6.1) \dagger$ & $51.5(10.2) \dagger$ & $69.0(7.0)$ exam & $37.8(13.2)$ \\
\hline Race: Caucasian & $92.9 \%$ & $93 \%+$ & $100 \% \dagger$ & $100.0 \%$ & $87.9 \%$ \\
\hline African American & $2.1 \%$ & $2.2 \%$ & $0.0 \%$ & $0.0 \%$ & $8.6 \%$ \\
\hline American Indian & $4.0 \%$ & $3.0 \%$ & $0.0 \%$ & $0.0 \%$ & $0.0 \%$ \\
\hline Asian & $0.7 \%$ & $0.9 \%$ & $0.0 \%$ & $0.0 \%$ & $2.0 \%$ \\
\hline Hispanic & $0.0 \%$ & $0.0 \%$ & $0.0 \%$ & $0.0 \%$ & $3.5 \%$ \\
\hline Other (unknown) & $0.2 \%$ & $0.4 \%$ & $0.0 \%$ & $0.0 \%$ & $0.0 \%$ \\
\hline Sex: Male & $70.6 \%$ & $72 \%+$ & $83 \%+$ & $43.0 \%$ & $55.2 \%$ \\
\hline Family history of CAD & $100.0 \%$ & $100 \%+$ & $58 \%+$ & $28.0 \%$ & \\
\hline Body Mass Index (SD) & $29.9(5.8)$ & $29.9(6.3)$ & $29.9(6.8)$ & $28.2(6.5)$ & \\
\hline Smoking & $78.0 \%$ & $84.0 \% \dagger$ & $72 \%+$ & $39.0 \%$ & \\
\hline Diabetes & $22.3 \%$ & $22.0 \%$ & $29.0 \%$ & $15.0 \%$ & \\
\hline Hypertension & $56.9 \%$ & $57 \%+$ & $66 \% \dagger$ & $66.0 \%$ & \\
\hline $\mathrm{MI}$ & $65.9 \% *$ & $89.0 \% *+$ & $100 \% \dagger$ & $0.0 \%$ & Data not available \\
\hline Sys/Dias BP (SD) & |40.|/84.0* (2।.5/| I.4) & $140.6 \dagger / 87.0 *(22.0 / 12.0)$ & $138.0 \dagger / 74.0(24.0 / 12.0)$ & $149.0 / 76.0(23.0 / 13.0)$ & \\
\hline Total Cholesterol (SD) & $239.1(64.8)$ & $235.0 \dagger(67.0)$ & $189.0 \dagger(56.0)$ & $189.0(43.0)$ & \\
\hline LDL (SD) & |46.| (54.3) & $161.0 \dagger(125.0)$ & $108+(42.0)$ & $105.0(35.0)$ & \\
\hline HDL (SD) & $38.67(16.3)$ & $40.0(14.0)$ & $39.0(12.0)$ & $51.0(19.0)$ & \\
\hline Triglycerides (SD) & 230.1 (138.8) & $221.0(157.0)$ & $226.0(239.0)$ & $169.0(133.0)$ & \\
\hline
\end{tabular}

*significant difference between eoCAD and ACS probands ( $p$ ? 0.05)

tsignificant difference between ACS probands and MI cases ( $p$ ? 0.05) 
been shown to be a better predictor of clinical outcome than extent of CAD [30]. Affected status was determined by the presence of significant CAD defined as a CADi ? 32 [31], as we have used for previous studies [22,23]. For patients older than 55 years of age, a higher CADi threshold (CADi ? 74) was used to adjust for the higher baseline extent of CAD in this group. Given the linkage to MI in the GENECARD study, we also selected a subgroup of Caucasian individuals who experienced MI from the overall CATHGEN group, similar to the GENECARD ACS families. MI was defined as documentation of MI in the medical history. Controls were defined as ?60 years of age, with no CAD as demonstrated by coronary angiography and no documented history of cerebrovascular or peripheral vascular disease, myocardial infarction, transplant, or interventional or surgical coronary revascularization procedures [32]. A comparison of clinical characteristics between GENECARD probands and CATHGEN MI cases and unaffected controls is presented in Table 1. As a replication data set, the CATHGEN sample provides $80 \%$ power to detect effect sizes between 1.25 and 1.45 , for allele frequencies ranging from 0.1 to 0.5 . The CATHGEN MI cases were also stratified into a young affected group (CAD AOO ? 55), which provides a consistent comparison for the GENECARD family study.

\section{Human donor aorta samples and expression}

Human aorta samples were collected from heart transplant donors as previously described [33]. DNA and RNA were isolated from each sample. Eighty-eight samples in total were analyzed representing fifty-eight unique samples, as 30 individuals had more than one sample. As harvested tissue was obtained from deceased heart donors, the clinical data associated with these aortas is very limited and consists of age, sex, and race (Table 1). Genotyping was performed using Applied Biosystems Taqman allelic discrimination assays and expression profiling was performed using Affymetrix GeneChip U95Av2 (Affymetrix, Santa Clara, CA). Expression signal intensity values were $\log _{2}$ transformed and normalized using quantile normalization. We analyzed cis effects of FAM5C variants on FAM5C expression using the Affymetrix tag 34442_at, representing the 3 ' end of FAM5C. Because some subjects had multiple samples while others did not, we treated each individual and sample separately. The expression level of the tag was modeled using multiple linear regression including age, sex, race and additive genotype. To account for repeated measures (i.e., multiple sections per subjects) and as a validation, a mixed model as implemented in the SAS PROC MIXED procedure was utilized (SAS Institute Inc., Cary, NC).

\section{Peak-wide SNP selection}

The approximate $30 \mathrm{Mb}$ region of linkage on chromosome 1q contains 138 genes (NCBI Build 36 in Ensembl).
We used an iterative fine mapping approach that involved selecting SNPs with a minor allele frequency of at least $5 \%$ in the Caucasian population spaced at 100 kilobases $(\mathrm{kb})$ [34]. These SNPs were intercalated with at least one previously identified and confirmed (validated) SNP to represent positional candidate genes from NCBI Build 35 (120 genes). When possible, coding SNPs, SNPs that altered a splice site or that were contained within putative regulatory regions of multi-species sequence conservation (chimp, mouse, rat, dog, chicken, Fugu, zebrafish) were selected for genotyping. If the gene was greater than 100 $\mathrm{kb}$ in size, multiple SNPs were selected using the same criteria. Additionally, SNPs were selected from regions that do not contain annotated genes at an average SNP to SNP distance of $100 \mathrm{~kb}$, while taking into account regions of multi-species sequence conservation.

Using these criteria, 231 intragenic and 226 intergenic SNPs were selected for genotype analysis within the chromosome 1q linkage region with an average spacing of 66 $\mathrm{kb}$. Twenty-seven genes contained validated coding SNPs with allele frequencies $>5 \%$; twenty-two genes contained synonymous SNPs with allele frequencies $>5 \%$; eleven SNPs are found within untranslated regions $\left(5^{\prime}\right.$ or $3^{\prime}$ UTR); and one hundred and seventy-one intronic SNPs were selected, the reference allele is conserved within fiftyfive of these (Additional files, Table 1).

\section{SNP genotyping}

A total of 457 SNPs were genotyped at two genotyping facilities. 384 SNPs were genotyped at the University of Washington through a grant from SeattleSNPs (see Availability and requirements section for URL). Genotyping in the GENECARD sample was performed by SeattleSNPs using the Illumina BeadStation 500 G SNP genotyping system (Illumina, San Diego, California, United States). Each Sentrix Array generates 384 genotypes for 96 individuals; within each individual array experiment, four samples purchased from Coriell were included as quality control samples. The Coriell samples were of Centre d'Etude du Polymorphisme Humain (CEPH) (Caucasian) origin, Asian and Hispanic ethnicity and were used for gender checking and to assess sample quality. In addition, one sample per plate was duplicated for internal quality control. These samples were used to identify possible sample plating errors and genotype calling inconsistencies. Twenty-two SNPs did not cluster well and were not called. The call rate for the remaining 362 SNPs was $99.8 \%$. One replicate error was identified in SNP rs2370025, all other SNPs yielded greater than $99.999 \%$ concordance among the replicates.

Ninety-five additional inter- and intragenic SNPs were assayed at the Center for Human Genetics using Taqman allelic discrimination assays. A total of 15 quality control 
samples - composed of six reference genotype controls in duplicate, two CEPH pedigree individuals, and one notemplate sample - were included in each quadrant of the 384-well plate. SNPs that showed mismatches on qualitycontrol samples were reviewed by an independent genotyping supervisor for potential genotyping errors. All SNPs examined were successfully genotyped for $95 \%$ or more of the individuals in the study. Error rate estimates for SNPs meeting the quality control benchmarks were determined to be less than $0.2 \%$.

\section{Statistical analysis}

All SNPs were tested for deviations ( $p$ ? 0.0001) from Hardy-Weinberg equilibrium (HWE) in the affected and unaffected race-stratified groups. Two SNPs deviated from HWE in the peak-wide association study, rs1503122 (cases) and rs438781 (cases and controls). Neither of these SNPs was statistically significant in our association analysis. Interestingly, rs438781 lies within a reported copy number polymorphism, which is most likely the cause of the disequilibrium. In CATHGEN, one SNP, rs9427746, significantly deviated from HWE ( $\mathrm{p}<0.0001)$ in the Caucasian control group. This deviation was neither due to mixed racial backgrounds as all of the samples were from Caucasian origin, nor was it due to assay dropout as all of our controls are randomly interspersed with our cases in the 384 well plates. This deviation is either a significant departure representing an association or due to random chance. Linkage disequilibrium between pairs of SNPs was assessed using the Graphical Overview of Linkage Disequilibrium package [35] and displayed using Haploview [36].

In the initial screen, two-point linkage using a dominant and recessive model was performed using Fastlink [37,38] and Homog [39] and family-based association was tested using the Association in the Presence of Linkage (APL) test [40]. We analyzed the GENECARD families together regardless of race because these families formed the basis of the original linkage evidence. We chose to use the APL test for family based association because this test incorporates data from affected sibling pairs with available parental data and unaffected siblings in the analyses, effectively using all available information in the GENECARD families. The APL software infers missing parental genotypes, appropriately accounts for the non-independence of affected siblings and calculates a robust estimate of the variance. APL results from markers with variance estimates of less than five are viewed as less reliable [41]. A single SNP in TROVE2 was significant in our original screen with a variance less than five and did not replicate.

In addition to APL, family-based association of FAM5C SNPs was performed using the Pedigree Disequilibrium Test (PDT) [42,43]. We employed this additional test at the gene level in order to obtain the most information about each polymorphism. The PDT test uses related trios and discordant sibships from extended pedigrees and like other family-based association tests is robust to population stratification. In order to determine if replicated SNPs could account for the MI linkage signal we employed Linkage and Association Modeling in Pedigrees (LAMP). LAMP estimates the degree of linkage disequilibrium (LD) between a candidate SNP and the putative disease locus through joint modeling of linkage and association $[44,45]$.

Allelic association in the CATHGEN MI cases and controls was evaluated using multivariable logistic regression modeling adjusted for sex, and known CAD risk factors (history of hypertension, history of diabetes mellitus, body mass index, history of dyslipidemia, and smoking history) as covariates. These adjustments could hypothetically allow us to control for competing genetic pathways that are independent risk factors for CAD, thereby allowing us to detect a separate CAD genetic effect. SAS 9.1 (SAS Institute, Cary, North Carolina, United States) was used for statistical analysis.

\section{FAM5C sequencing}

To identify novel SNPs within seven regions of multi-species sequence conservation localized to the last intron of FAM5C (see Additional files, Figure 1, arrows), PCR amplicons were generated using standard conditions and sequenced using ABI Big Dye v3.1 and an ABI 3730 automated sequencer (primers available upon request). Sequencing data were analyzed using Sequencher software (GeneCodes, Ann Arbor, Michigan, United States). All amplicons were generated within 16 affected and 16 unaffected GENECARD individuals (16 Caucasian males and 16 Caucasian females). Primer sets for each region are listed in Additional files, Table 2.

\section{Aortic endothelial and smooth muscle cell culture}

Cryopreserved human aortic smooth muscle (AoSMC) and human aortic endothelial cells (HAEC) were obtained from Lonza (Walkersville, MD) at passage 3 and cultured using SGM-2 or EGM-2 media (Lonza) until the indicated passage. Cells were grown in T-75 SoLo Flasks Nunclon $^{\mathrm{TM}}$ ? (NUNC, Rochester, NY) according to manufacturer's instructions (see Availability and requirements section for URL).

\section{Reverse transcriptase PCR (RT-PCR)}

RNA from 20 human tissues (Human Total RNA Master Panel II) was obtained from Clontech (Mountain View, CA). Lot number 6020107 contained RNA from the following tissue types: Fetal Brain, Spinal Cord, Skeletal Muscle, Lung, Trachea, Fetal Liver, Liver, Bone Marrow, Kidney, Thymus, Thyroid, Adrenal Gland, Salivary Gland, 
Table 2: LAMP Analysis in GENECARD ACS families and replication in CATHGEN MI cases and controls

\begin{tabular}{|c|c|c|c|c|c|c|c|c|c|c|c|c|}
\hline \multirow[t]{2}{*}{ SNP } & \multirow[t]{2}{*}{$\begin{array}{l}\text { LOCATION } \\
\text { (bp) }\end{array}$} & \multicolumn{2}{|c|}{ Alleles } & \multicolumn{2}{|c|}{$\begin{array}{l}\text { LINKAGE TEST } \\
\quad(\mathrm{df}=3)\end{array}$} & \multicolumn{2}{|c|}{$\begin{array}{l}\text { ASSOCIATION } \\
\text { TEST }(\mathrm{df}=\mathrm{I})\end{array}$} & \multicolumn{2}{|c|}{$\begin{array}{l}\text { OTHER LINKED } \\
\text { VARIANTS }(\mathrm{df}=2)\end{array}$} & \multicolumn{2}{|c|}{ CATHGEN MI Logistic regression $†$} & \multirow[t]{2}{*}{$\begin{array}{l}\text { CATHGEN Minor } \\
\text { Allele Frequency }\end{array}$} \\
\hline & & Major & Minor & LOD & pvalue & LOD & pvalue & LOD & pvalue & Allele pvalue & Allele OR $(95 \% \mathrm{Cl})^{*}$ & \\
\hline RS75। 4392 & $188,323,178$ & C & $g$ & 2.95 & 0.004 & 0.33 & 0.220 & 1.69 & 0.020 & - & - & - \\
\hline RSI092050I & $188,328,568$ & $A$ & $\mathrm{t}$ & 2.98 & 0.003 & 0.96 & 0.040 & 2.27 & 0.005 & 0.018 & $0.612(0.408-0.919)$ & 0.18 \\
\hline RSI2I 42564 & $188,338,626$ & $\mathrm{C}$ & $\mathrm{t}$ & 2.80 & 0.005 & 1.43 & 0.010 & 2.53 & 0.003 & 0.322 & $0.799(0.508-1.257)$ & 0.11 \\
\hline RS2185836 & $188,349,217$ & $A$ & $g$ & 2.89 & 0.004 & 0.76 & 0.060 & 2.82 & 0.002 & 0.273 & $0.79 \mid(0.521-1.202)$ & 0.45 \\
\hline RS2419370 & $188,375,504$ & $\mathrm{~T}$ & c & 2.50 & 0.009 & 0.56 & 0.110 & 2.49 & 0.003 & 0.003 & $1.925(I .25 I-2.96 I)$ & 0.44 \\
\hline RS2990996 & $|88,4| \mid, 850$ & $\mathrm{C}$ & a & 3.19 & 0.002 & 0.16 & 0.400 & 3.18 & 0.001 & 0.115 & $1.44 \mid(0.915-2.27 I)$ & 0.50 \\
\hline RS8I5343 & $188,422,256$ & $\mathrm{C}$ & $\mathrm{t}$ & 2.97 & 0.003 & 0.34 & 0.210 & 2.31 & 0.005 & 0.005 & $0.574(0.392-0.842)$ & 0.39 \\
\hline RSI89I586 & $188,430,617$ & $\mathrm{~T}$ & $g$ & 2.95 & 0.004 & 0.04 & 0.700 & 2.93 & 0.001 & 0.003 & $0.563(0.385-0.823)$ & 0.23 \\
\hline RS9427746 & $188,438,263$ & G & c & 2.86 & 0.004 & 0.01 & 0.810 & 2.50 & 0.003 & 0.007 & $0.587(0.399-0.863)$ & 0.40 \\
\hline RSI0920678 & $188,506,530$ & G & a & 2.99 & 0.003 & 0.01 & 0.850 & 2.77 & 0.002 & 0.159 & $0.753(0.508-1.117)$ & 0.43 \\
\hline RS480692 & $188,526,284$ & $\mathrm{~T}$ & c & 3.29 & 0.002 & 0.41 & 0.200 & 3.42 & 0.000 & 0.028 & I.59। (1.052-2.405) & 0.43 \\
\hline RSI 2724000 & $188,618,300$ & $\mathrm{C}$ & $\mathrm{t}$ & 2.78 & 0.005 & 0.04 & 0.660 & 2.60 & 0.003 & 0.031 & $0.645(0.434-0.961)$ & 0.17 \\
\hline RS872177 & $188,659,068$ & $\mathrm{~T}$ & a & 2.93 & 0.004 & 0.05 & 0.600 & 2.90 & 0.001 & 0.188 & $0.776(0.533-1.132)$ & 0.31 \\
\hline RS2134098 & $188,660,894$ & G & c & 2.82 & 0.005 & 0.89 & 0.040 & 3.00 & 0.001 & 0.131 & $0.679(0.41 \mathrm{I}-1.122)$ & 0.08 \\
\hline RSI0920722 & $|88,694,7| 7$ & A & $\mathrm{t}$ & 2.65 & 0.007 & 0.07 & 0.600 & 2.37 & 0.004 & 0.009 & $0.589(0.397-0.874)$ & 0.19 \\
\hline RSI0920725 & $188,707,160$ & $\mathrm{~T}$ & c & 2.65 & 0.007 & 0.13 & 0.400 & 2.45 & 0.004 & 0.007 & $0.584(0.394-0.865)$ & 0.20 \\
\hline RSII58I737 & $188,726,896$ & G & $\mathrm{a}$ & 2.87 & 0.004 & 0.18 & 0.400 & 2.76 & 0.002 & 0.031 & $0.642(0.429-0.960)$ & 0.16 \\
\hline
\end{tabular}

*Odds Ratio (OR) calculated for minor allele, - not tested

fadjusted for sex, history of hypertension, history of diabetes mellitus, body mass index, history of dyslipidemia, and smoking history

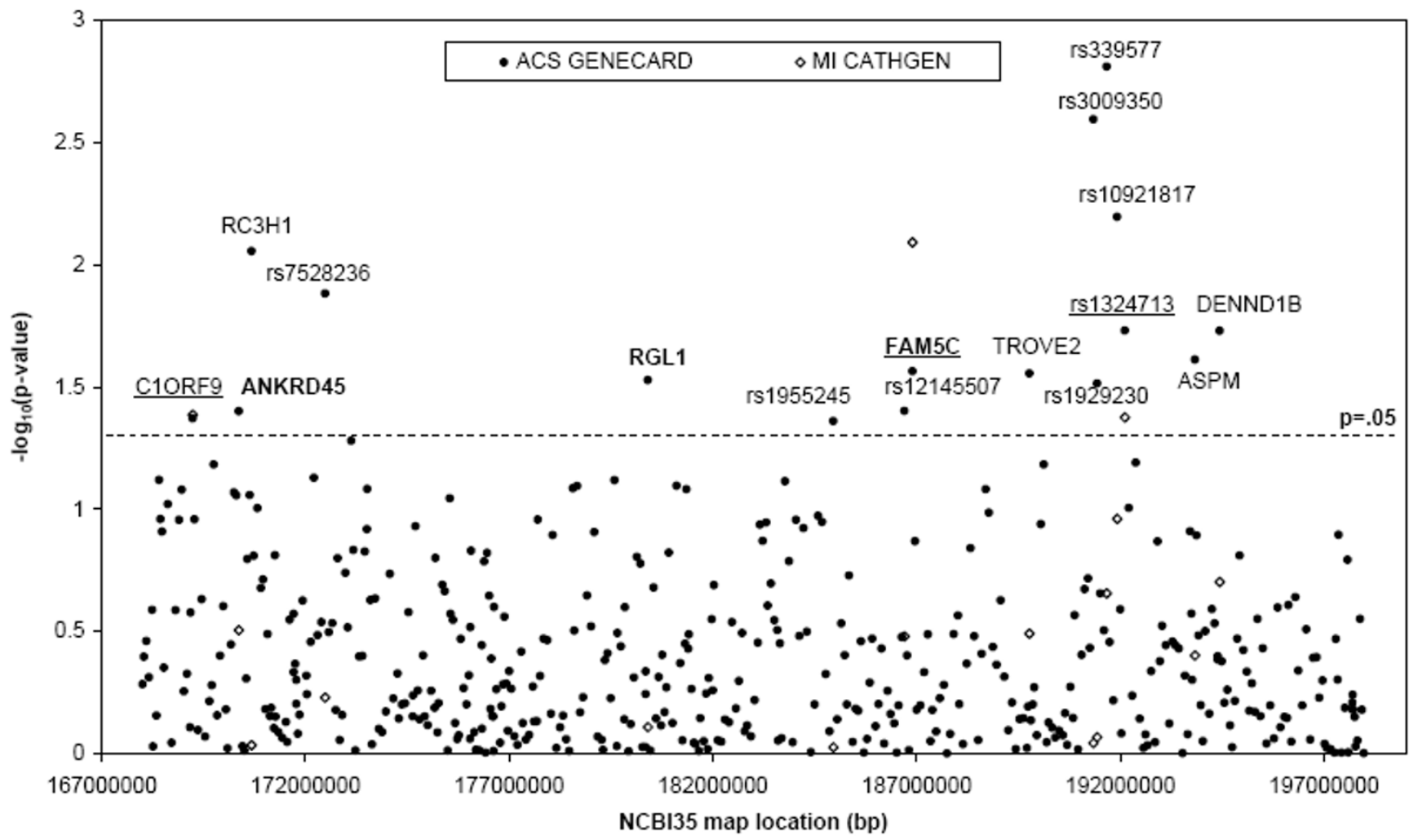

Figure I

Chromosome I peak-wide mapping of genes involved in myocardial infarction. 457 SNPs were genotyped across the I LOD down region of linkage on chromosome I in the GENECARD ACS sample. Association was assessed using APL. The - $\log _{10}$ of the $p$-value is plotted according to chromosome position (closed circles). Markers with a p-value less than 0.05 fall above the dashed line; labels identify these genes and intergenic SNPs. Markers in bold exhibited modest evidence for linkage (LOD ? I) in two point analysis. Sixteen markers that were associated ( $P$ ? 0.05 ) in the GENECARD ACS sample were genotyped in a MI case-control population (open circles). Markers which show replication are underlined. 
Uterus, Testes, Prostate, and Placenta. RNA from cultured aortic smooth muscle and endothelial cells was isolated using a Ribopure Kit from Applied Biosystems (Foster City, CA). cDNA was synthesized using the protocol for cDNA synthesis in the Illumina Total Prep RNA Amplification kit from Applied Biosystems (Foster City, CA). Primers corresponding to exon 6 and exon 7 of FAM5C were used for PCR from cDNA (5'-ACAACAGTGACTTTGAGGAATCAGA-3' and 5'-GCGCTGAAAATTAGAATCCATTG-3'). Primers corresponding to exons 8 and 9 of GAPDH were used as a template control (5'-CTCCTCCACCTTTGACGCTG-3', and 5'-AGGGGAGATTCAGTGTGGTG-3'). $20 \mathrm{ng}$ of cDNA template was used for each reaction and Platinum Taq polymerase (Invitrogen, Carlsbad, CA) was used for all PCR reactions. PCR reaction conditions were as follows: Step 1: $95^{\circ} \mathrm{C}$ for $5 \mathrm{~min}-$ utes, Step 2: 30 cycles (FAM5C) or 20 cycles (GAPDH) of $95^{\circ} \mathrm{C}$ for 1 minute followed by $62^{\circ} \mathrm{C}$ for 1 minute, and $72^{\circ} \mathrm{C}$ for $1 \mathrm{~min}$, and Step $3,72^{\circ} \mathrm{C} 10 \mathrm{~min}$.

\section{FAM5C real time $R T-P C R$}

Applied Biosystems Taqman Gene expression assays were used to perform quantitative (real time) RT-PCR (FAM5C, Hs00982332_m1 and GAPDH, Hs02758991_g1). The following reaction components were used for each probe: 2 uL cDNA, 5 ul Custom TaqMan SNP Master Mix (Applied Biosystems, Foster City, CA), 0.5 ul of assay, and 2.5 ul water. Reactions were performed in a single 384 well plate in triplicate using an ABI PRISM ${ }^{\circledR} 7900$ HT Sequence Detection System. PCR reaction conditions were as follows: Step 1: $50^{\circ} \mathrm{C}$ for 2 minutes, Step 2: $95^{\circ} \mathrm{C}$ for 10 minutes, Step 3: 40 cycles of $95^{\circ} \mathrm{C}$ for 15 seconds followed by $60^{\circ} \mathrm{C}$ for 1 minute. Expression relative to GAPDH was calculated using $2^{\text {?Ct }}[46]$ and levels were normalized to heart expression.

\section{Results \\ Peak-wide genotyping and analysis in GENECARD ACS linkage Peak}

457 SNPs, at an average spacing of 66 kilobases, were genotyped in the one LOD down support interval (169-199 $\mathrm{Mb}$ ) of the GENECARD chromosome 1q ACS linkage peak (see Additional files, Table 1). Family-based association performed in the ACS families using APL identified sixteen SNPs that were significant at p ? 0.05 (Figure 1, Additional files, Table 3), three of which also displayed linkage: rs10912660 in the ankyrin repeat domain 45 gene (ANKRD45), rs12092963 in the ral guanine nucleotide dissociation gene (RGL1), and rs1891586 in FAM5C (Figure 1, bold). The clinical characteristics comparing the ACS probands in GENECARD to the MI cases in CATHGEN show the suitability of this group for replication (Table 1). Three of the sixteen SNPs replicated in the CATHGEN MI cohort at p ? 0.05 (Figure 1, underlined). Two SNPs, rs2239816 and rs1891586, reside within genes, chromosome 1 open reading frame 9 protein (C1orf9) and FAM5C, and the third within an intergenic region (rs1324713).

A SNP found within the first intron of the tumor necrosis factor superfamily 4 gene (TNFSF4), rs3850641, residing within the chromosome 1q linkage peak, has previously shown to be associated with MI in two independent populations [47], but although it was linked, was not associated in the GENECARD samples (Additional files, Table 4). LAMP analysis determined that this SNP does not account for the linkage observed in these families (data not shown).

\section{tagSNP genotyping and analysis}

We chose haplotype tagging SNPs in C1orf9, FAM5C and the intergenic region 100 kilobases upstream and downstream of rs1324713. None of the additional genotyped tagSNPs in C1orf9 or the intergenic region displayed both association and linkage (Additional files, Table 4). However, the original C1orf9 SNP identified in the screen, rs2239816, is significantly associated in both GENECARD ACS (APL, p = 0.05) and CATHGEN MI samples (allele p $=0.04)$ and results in an amino acid change at position 11 (Pro11Ser). This SNP does not, however, explain the linkage seen in our ACS family subset.

A single SNP in FAM5C (rs1891586) from the peak-wide screen showed both linkage and association in the ACS sample (maximum LOD $=1.54, \mathrm{p}=0.027$ ). To further fine map the gene we selected 67 haplotype tagging SNPs using HapMap data and Tagger [48] (capturing 100\% of the alleles at $\mathrm{r}^{2}=0.8$ in the European population) from a region that spanned FAM5C and 15 kilobases upstream and 5 kilobases downstream of the gene. Only 48 of these SNPs had minor allele frequencies $>5 \%$ and were informative given the small sample size when genotyped in the GENECARD ACS families. Sixteen of these SNPs displayed linkage (LOD ? 1 in either model) and/or association (p ? 0.05) (Figure 2, Figure 3, Additional files, Table 5), with three SNPs (rs2134098, rs12142564 and rs10920501) partially accounting for the linkage signal on chromosome 1 (Table 2, compare association test to other linked variants) by LAMP analysis $[44,45]$. In the CATHGEN sample, twelve of these sixteen SNPs were significantly associated with MI (Table 2), however, only one of the three SNPs that partially accounted for linkage in GENECARD (rs10920501) was associated with MI in CATHGEN. Interestingly, when we stratified our MI sample by age of onset (see methods), we found that the strength of the overall rs10920501 signal increased within the young affected group (T allele, $\mathrm{p}=0.009$, $\mathrm{OR}=0.539$ ). This SNP tags $\left(\mathrm{r}^{2}\right.$ ? 0.8) 6 additional SNPs that flank the last exon on FAM5C (see Addition files, Figure 1). This 


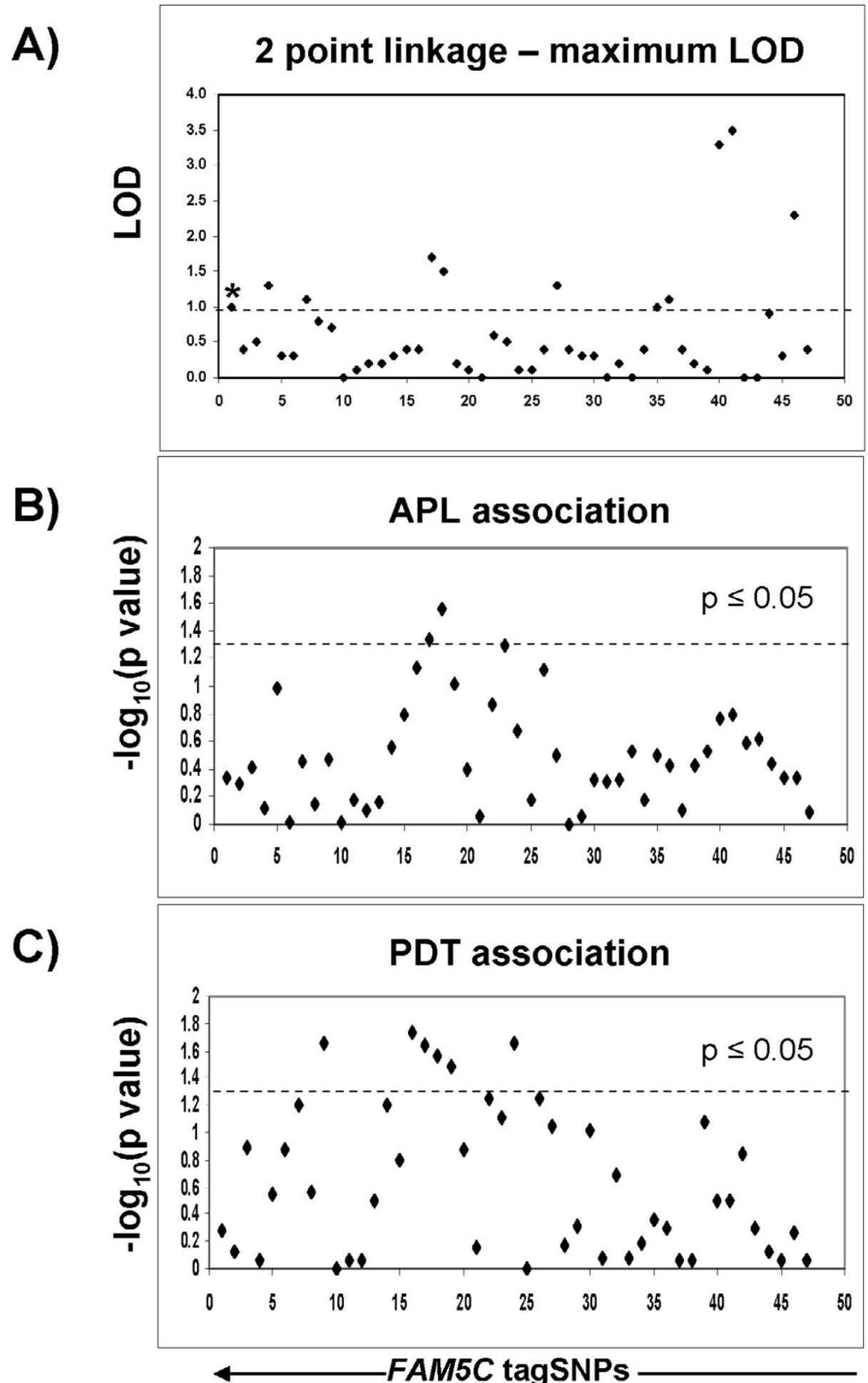

Figure 2

FAM5C tagSNPs are associated and linked to acute coronary syndrome. 47 haplotype tagging SNPs were selected to span the length of FAM5C as well as $15 \mathrm{~kb}$ up and $5 \mathrm{~kb}$ downstream of the gene to account for potential regulatory elements. Parametric linkage (A), APL association (B) and PDT association (C) were assessed. SNPs that were linked (LOD ? I) and/or associated ( $P$ ? 0.05) were selected for replication (markers that fall above the dashed lines, $n=16)$. * denotes rs I092050I. 


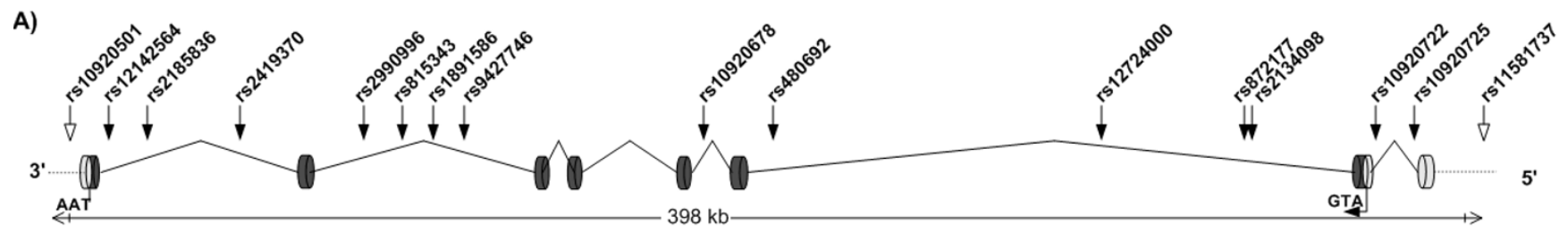

B)

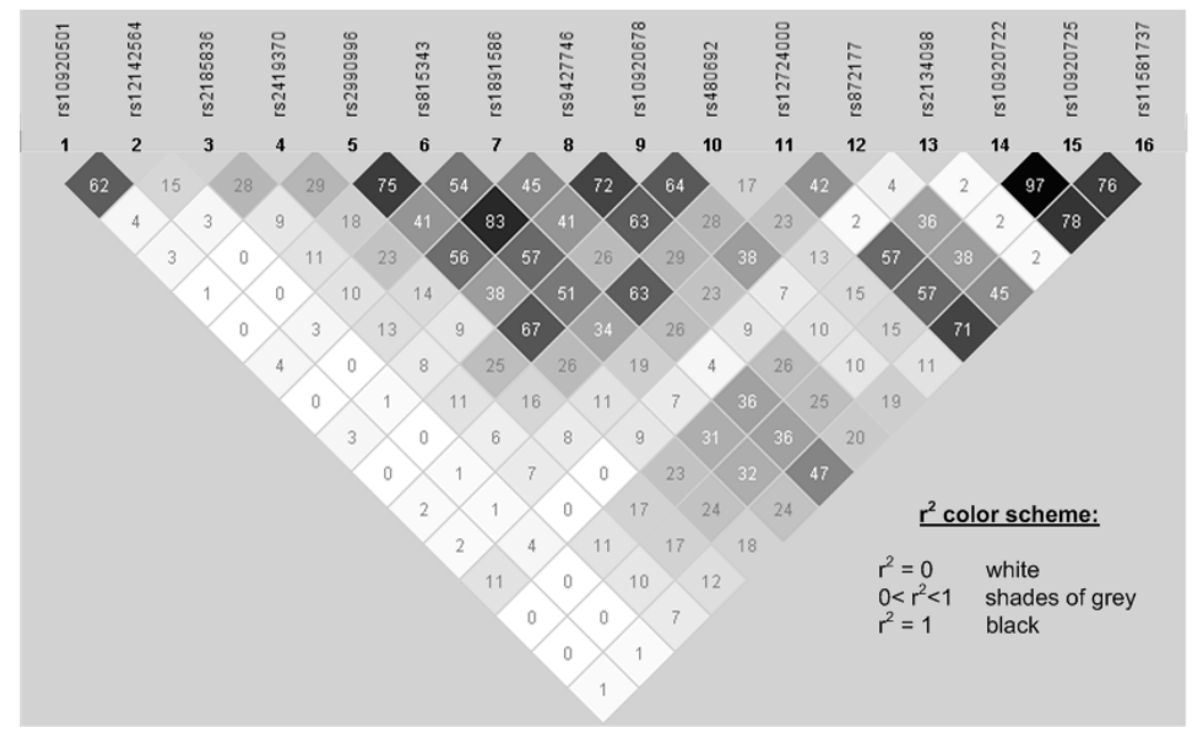

Figure 3

Schematic of FAM5C gene structure and pairwise LD between FAM5C SNPs. (A) Sixteen of forty-seven tagSNPs in FAM5C that were tested for replication and linkage are shown. SNPs with an open arrow are found outside of the gene. All sixteen SNPs represent 16 of 47 linkage disequilibrium (LD) blocks. (B) LD was estimated in one unaffected Caucasian individual from each non-redundant GENECARD ACS sibling pair. A similar pattern of LD was observed using the CATHGEN MI affected and unaffected individuals.

SNP is in linkage equilibrium $\left(r^{2}=0.04\right)$ with rs1891586, the original SNP identified in the peakwide screen.

\section{Sequencing FAM5C conserved regions in intron 7}

We noted blocks of multi-species sequence conservation in the last intron of FAM5C and hypothesized that the causal SNP, in LD with rs10920501, may lie in one of these regions. The allele frequency of rs10920501 is approximately $16 \%$ in the Caucasian population. We rationalized that a causal SNP that was in LD with rs10920501 would be at a similar allele frequency. Given Kruglyak and Nickerson's estimates [49] we performed sequencing across 32 individuals that should allow for a SNP detection rate between $99 \%$ and $99.9 \%$ at a minor allele frequency of $10 \%$. The seven conserved regions (see Additional files, Figure 1, arrows) were PCR amplified from 16 Caucasian cases and 16 Caucasian controls using standard conditions and sequenced. No novel SNPs were identified (data not shown).

\section{FAM5C allele specific gene expression}

We next asked if rs10920501 (or an unidentified SNP in linkage disequilibrium with rs10920501) was functionally relevant to CAD. We genotyped a set of aorta samples that we had previously collected for expression analysis [33] and we found that the inheritance of the T allele of rs10920501 is significantly associated with a reduction in the expression of FAM5C in aorta (Figure 4) (p = 0.03 in generalized model; $\mathrm{p}=0.02$ in mixed regression model to account for repeated measures). Since the $\mathrm{T}$ allele is protective in our sample (allelic odds ratio, 0.609 in CATHGEN, Table 2) and carriers of the T allele show decreased FAM5C gene expression in aorta, higher expression of FAM5C in the cells that make up the artery may be related to increased risk of MI. Because a QTL for MCP-1 in the Framingham Heart Study overlaps with the GENECARD ACS linkage peak, we also tested the effect of rs 10920501 on MCP-1 expression levels in the aorta, but found no evidence for any relationship (data not shown). 


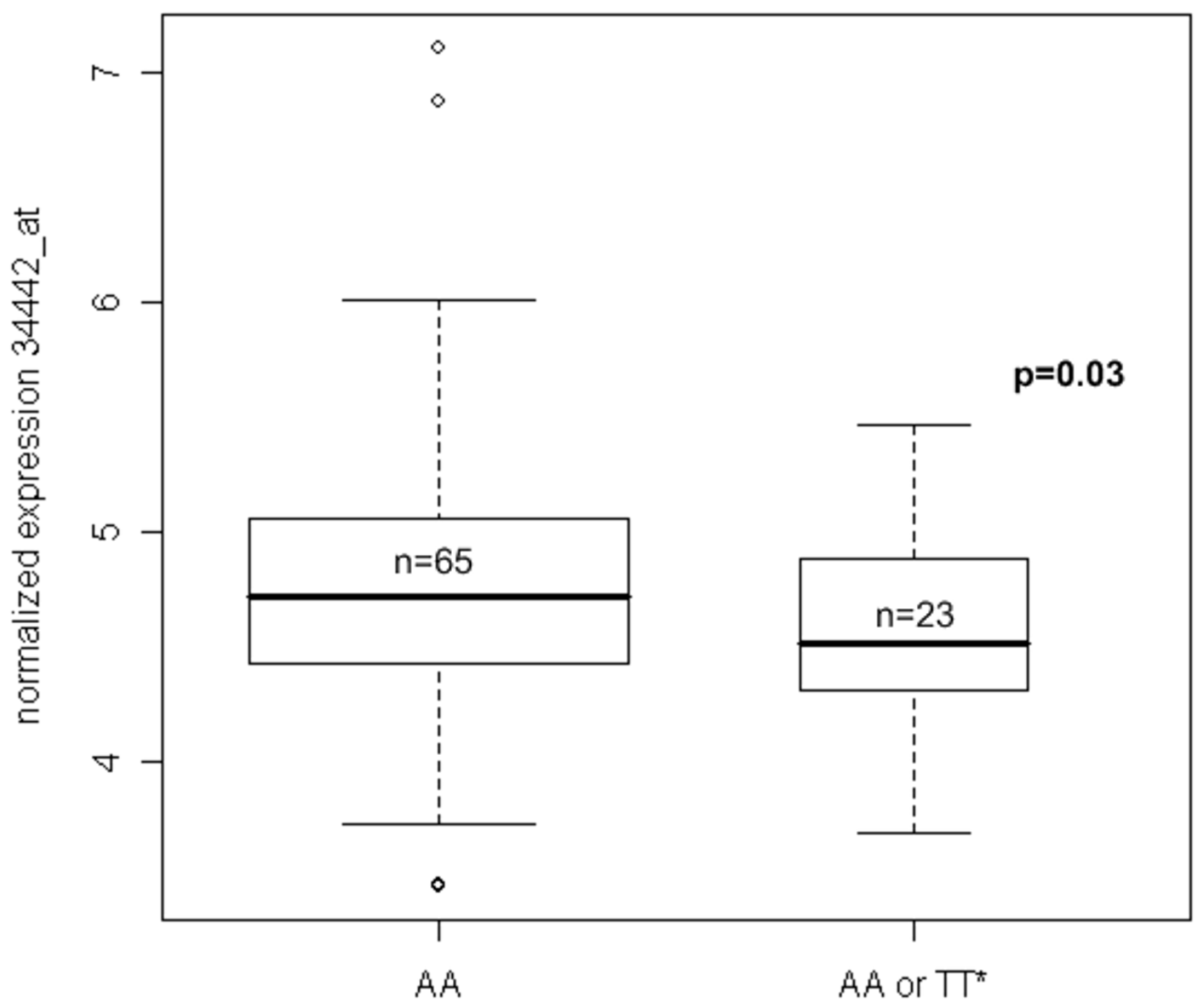

rs10920501 genotype

Figure 4

FAM5C expression is modulated by the T allele of rs I 092050 I. Eighty-eight human donor aorta were harvested, genotyped for rs 1092050I, and assayed for FAM5C expression using Affy tag 34442_at. Box plots are shown for gene expression by genotype. The presence of the T allele of rs I092050 I significantly reduces FAM5C expression. The $p$-value shown is for the generalized model adjusted for age, sex, and race. $* n=I$ in the TT genotype group.

FAM5C is expressed in proliferating human aortic smooth muscle cells and expression changes with passage

Given that FAM5C is expressed in human aorta, we sought to determine if FAM5C is expressed in smooth muscle and endothelial cells, the primary constituents of the human aorta. We cultured proliferating aortic smooth muscle (AoSMC) and human aortic endothelial cells (HAEC) and isolated RNA. Reverse transcriptase PCR (RT-PCR) identified FAM5C expression in both endothelial and aortic smooth muscle cells (Figure 5A, lanes 2, 3, and 4). In order to determine if FAM $5 \mathrm{C}$ expression was specific to the brain and arteries, we assayed expression of FAM5C in 20 human tissues and found that it is expressed in many different tissue types at varying levels (Additional files, Figure 2).

We noted that the expression levels of FAM5C appeared to vary with AoSMC passage (compare p. 5 and p. 8 AoSMC 
A)

B)

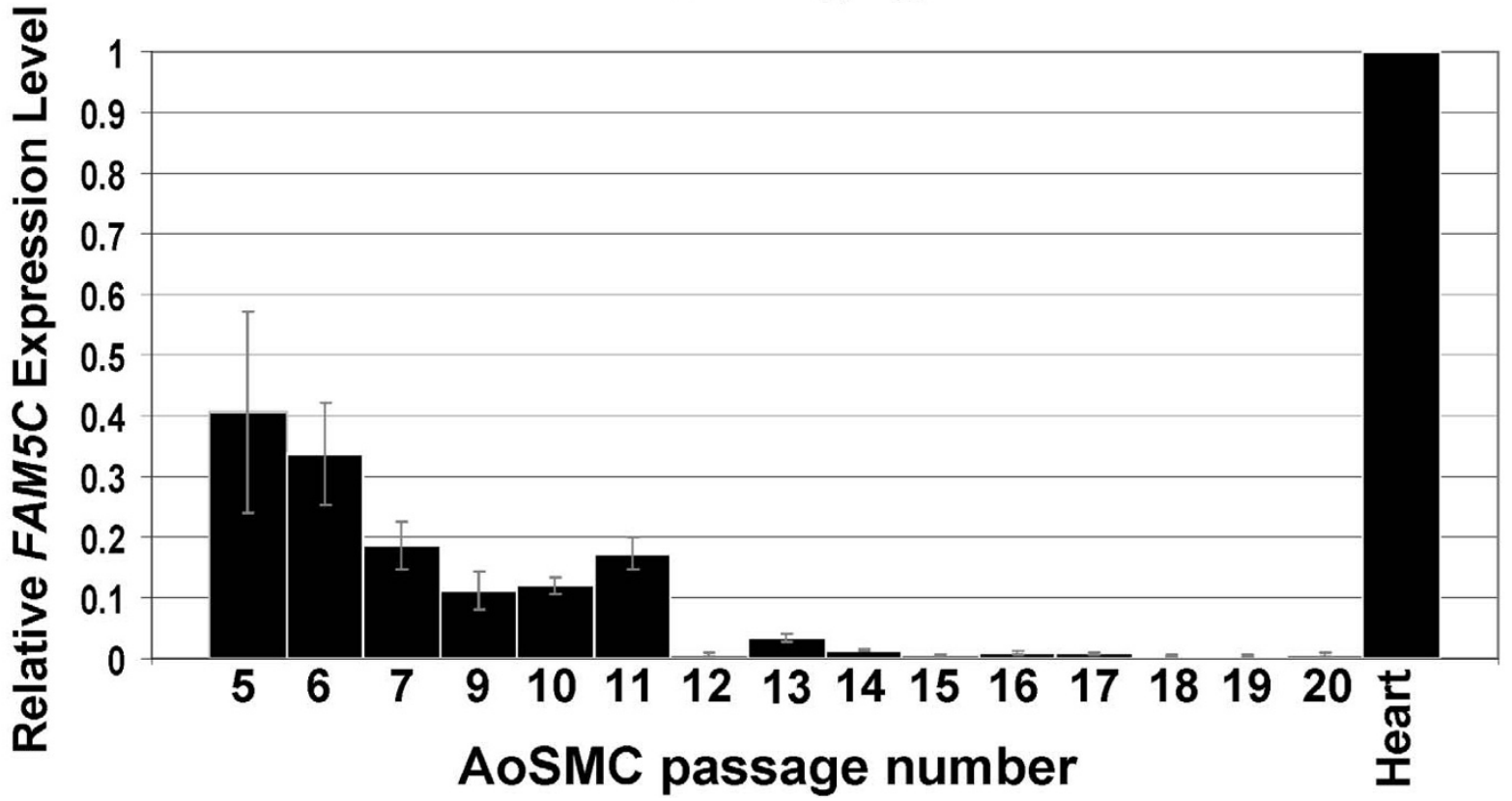

\section{Figure 5}

FAM5C is expressed in aortic endothelial and smooth muscle cells. (A) RT-PCR was performed on RNA derived from the cerebellum (control) and proliferating aortic endothelial (HAEC, passage 6) and smooth muscle cells (AoSMC, passage 5 and 8). (B) Real time RT-PCR was performed on RNA isolated from serially passed AoSMC. Aliquots were taken at every passage and experiments were performed in triplicate. FAM5C and GAPDH expression were assayed at the same time and GAPDH was used to normalize all samples. The expression level was calculated relative to heart RNA (control). Standard deviation was calculated for each experiment and is indicated by grey bars.

RT-PCR Figure 5 and Additional files, Figure 2) and therefore hypothesized that FAM5C levels may change with proliferative capacity and cellular senescence. Sub-culturing of primary cells, such as AoSMC, results in a progressive reduction of proliferation until the cells reach senescence, described as Hayflick's limit [50]. We serially cultured AoSMC derived from a 29 year old Caucasian male donor until senescence (passage 20) indicated by cessation of proliferation and an enlarged flattened cell morphology. We measured the level of FAM5C expression in triplicate during each passage (passage 8 RNA was depleted) using real time RT-PCR. We found that FAM5C levels decrease as cells age in culture (Figure 5B). 


\section{Discussion and Conclusion}

We herein report the results of fine-mapping a linkage peak for MI and identifying a novel MI susceptibility gene, FAM5C. We show that polymorphisms in FAM5C are associated with $\mathrm{MI}$ in two independent samples and that the SNP, which partially accounts for the linkage in our GENECARD ACS peak, is also significantly associated with changes in FAM5C gene expression in the human aorta. To begin to address the functional role of FAM5C in MI, we observed that FAM5C is expressed in the human aorta and that its transcript levels decrease with increasing passage of AoSMC, suggesting that the level of gene expression may play a role in proliferation and senescence of this cell type.

FAM5C was originally identified in the mouse brain as a gene that is induced by bone morphogenic protein and retinoic acid signaling (BRINP3 gene) [51] and has recently been shown to be over-expressed in human pituitary tumors [24]. In the aforementioned study, the authors show that FAM5C is localized to the mitochondria and that over-expression of this molecule leads to increased proliferation, migration, and invasion of nontumorogenic pituitary cells (the opposite being true for knockdown of FAM5C). Through complex signaling cascades, mitochondria have the ability to activate multiple pathways that modulate both cell proliferation and, conversely, promote cell arrest and programmed cell death (reviewed in [52,53]). FAM5C localization to the mitochondria and its putative role in regulating cell proliferation and migration provide an intriguing hypothesis for the role of FAM5C in smooth muscle cells and the formation and vulnerability of the atherosclerotic plaque. SMCs move from a contractile state to a proliferative, migratory state in the presence of endothelial cell dysfunction at the initiation phase of plaque formation. They migrate into the region of plaque formation and form the fibrous cap that covers the plaque which is prone to rupture (reviewed in [25]). FAM5C levels could play a role in the initiation of smooth muscle cell proliferation and migration and/or in the disintegration of the smooth muscle cell in the fibrous cap. We are currently conducting experiments to determine if FAM5C levels have effects on smooth muscle cell proliferation, migration, apoptosis and senescence.

While our analysis was primarily aimed at an MI phenotype, our ACS family sample included a limited number of individuals with unstable angina. As a result the power to detect a distinct MI effect may be somewhat lower in our ACS family data set. Nevertheless, we observed consistent and replicated results in the MI case-control set and in the ACS family data set, suggesting that our results are robust to potential phenotypic heterogeneity. In addition, two recent WGA studies from the Framingham Heart Study have identified significant association between atrial fibrillation (AF) and FAM5C (rs1604355), and also for left atrial size (LAS) and FAM5C (rs1935881) [54,55]. Both of these SNPs are in low LD ( $\mathrm{r} 2<0.1)$ with rs10920501; however, a SNP within the linkage disequilibrium bin containing rs10920501 was not represented on the SNP chip used in these studies, leaving open the possibility that rs 10920501 may also play a role in these phenotypes. Although atrial fibrillation and left atrial size are very different phenotypes from MI, these data, together with the data presented in this paper, suggest that further genetic and functional studies are warranted to determine the role of FAM5C and variation within this gene in diverse diseases in cardiovascular tissues.

Three separate studies identified linkage to the same region of chromosome 1, the Framingham Heart Study [16], the IRAS family study [17], and the GENECARD study [15]. Through careful fine mapping of a linkage peak for an extreme CAD phenotype, MI, we have defined a single gene that can partially account for the linkage in this peak. The relationship between MCP-1 levels, metabolic syndrome, MI, and FAM5C still remains to be defined. Inflammation lies at the heart of these pathophysiologies. We know that inflammation is an important part of metabolic syndrome [56], individuals with metabolic syndrome are at higher coronary disease risk [57], and metabolic syndrome increases the risk of an event (MI, revascularization, or cardiac death) in individuals with a family history of MI [58]. In addition, vascular SMC pathophysiology is related to inflammation which could explain the MCP-1 QTL linkage. Further work is clearly indicated in this area.

One of the more difficult aspects of genetic association analysis is how to appropriately correct for multiple comparisons in evaluating the statistical significance of any given result. Possible approaches range from the most conservative Bonferroni correction, to estimation of false discovery rate [59], to weighted corrections of combined data, to no correction at all. We are aware that the p-values presented in this paper were not corrected for multiple comparisons. Our enthusiasm for FAM5C as an MI susceptibility gene is based on the observed replication of association results from multiple independent data sets and different approaches. The line of reasoning has several parts. First, rs10920501 represents a significant marker that can partially account for the linkage signal in our ACS families, and the statistical significance of the observation replicates in an independent case-control sample. Second, the probability of observing three or more significant results out of sixteen in the independent case-control sample under the null hypothesis that there is no association ( $\mathrm{p}$ ? 0.05) is 0.043. Third, we have observed that the level of the transcript in the aorta is associated with genetic variation this SNP (or a SNP LD with 
it). Last, we observed that levels of FAM5C change with passage in AoSMC, implying that genetic variation in the gene might be involved in AoSMC cellular processes involved in the formation of unstable atherosclerotic plaque leading to MI. Further work to elucidate the function of FAM5C in MI, including the MI-associated polymorphisms and its downstream targets, is necessary in order to begin to understand the role this mitochondrial molecule plays in this disease.

\section{Competing interests}

The authors declare that they have no competing interests.

\section{Availability and requirements}

SeattleSNPs: http://pga.mbt.washington.edu

Lonza: http://www.lonzabioscience.com

\section{Authors' contributions}

JJC, JFD, and SGG carried out the molecular genetic studies. JJC and JFD carried out the RTPCR and real time RTPCR. ABH, DRC, XL, SN and CH performed the statistical analysis. TW performed bioinformatic analyses. DS provided expression data from human aorta. DCC, VM, CBG, CJHJ, WEK provided the clinical data and samples for genotyping. JJC, SHS, ERH and SGG conceived of the study, and participated in its design and coordination and helped to draft the manuscript. All authors read and approved the final manuscript.

\section{Additional material}

\section{Additional file 1}

Figure 1. The location of rs10920501 and the SNPs it represents. UCSC genome browser output for chr1:188,266,509-188,418,688 basepairs (build 36) containing the 3' end of the FAM5C gene. The sequenced regions of high conservation present in the last intron of FAM5C are indicated by black arrows.

Click here for file

[http://www.biomedcentral.com/content/supplementary/14712350-9-33-S1.pdf]

\section{Additional file 2}

Figure 2. FAM5C is ubiquitously expressed in human tissues. FAM5C RT-PCR was performed on RNA derived from 20 human tissues (as labeled) and proliferating aortic endothelial (HAEC, passage 6) and smooth muscle cells (AoSMC, passage5 and 8). GAPDH is displayed to assess template input.

Click here for file

[http://www.biomedcentral.com/content/supplementary/14712350-9-33-S2.eps]

\section{Additional file 3}

Table 1. The list of SNPs genotyped in the peakwide screen. Click here for file

[http://www.biomedcentral.com/content/supplementary/14712350-9-33-S3.doc]

\section{Additional file 4}

Table 2. A list of primer sets used to amplify genomic regions of FAM5C for sequencing.

Click here for file

[http://www.biomedcentral.com/content/supplementary/14712350-9-33-S4.doc]

\section{Additional file 5}

Table 3. Sixteen significant SNPs identified in peakwide screen of chromosome 1 ACS linkage peak and replication of three associated SNPs in CATHGEN MI case-control sample.

Click here for file

[http://www.biomedcentral.com/content/supplementary/14712350-9-33-S5.doc]

\section{Additional file 6}

Table 4. tagSNP genotyping results for $\mathrm{C} 1 \mathrm{orf9}$ and an intergenic region surrounding rs1324713 in GENECARD ACS families.

Click here for file

[http://www.biomedcentral.com/content/supplementary/14712350-9-33-S6.doc]

\section{Additional file 7}

Table 5. tagSNP genotyping results for FAM5C in GENECARD ACS families.

Click here for file

[http://www.biomedcentral.com/content/supplementary/14712350-9-33-S7.doc]

\section{Acknowledgements}

We are appreciative of the subject volunteers' participation in the GENECARD and CATHGEN studies. We would also like to acknowledge the essential contributions of the following individuals to making this publication possible: Elaine Dowdy, the GENECARD Investigators Network, the CATHGEN Steering Committee Members, Margaret Pericak-Vance, Jeffery M. Vance, Pascal Goldschmidt-Clermont, Neil Freedman, Beth Sutton and the staff at the Center for Human Genetics for their innumerable contributions to this manuscript. Genotyping provided through the SeattleSNPs PGA Early Investigator Program (HL66682). This work was supported by $\mathrm{NIH}$ grants K99HL0894I2 (Connelly), HL073389 (Hauser), and HL73042 (Kraus).

\section{References}

I. Rosamond W, Flegal K, Friday G, Furie K, Go A, Greenlund K, Haase N, Ho M, Howard V, Kissela B, Kittner S, Lloyd-Jones D, McDermott M, Meigs J, Moy C, Nichol G, O'Donnell CJ, Roger V, Rumsfeld J, Sorlie $P$, Steinberger J, Thom T, Wasserthiel-Smoller S, Hong Y, for the American Heart Association Statistics Committee and Stroke Statistics Subcommittee: Heart Disease and Stroke Statistics--2007 Update: A Report From the American Heart Association Statistics Committee and Stroke Statistics Subcommittee. Circulation 2007, II 5:e69-17I.

2. Organization WH: The World Health Report 2002 - Reducing Risks, Promoting Healthy Life. 2002. 
3. Shea S, Ottman R, Gabrieli C, Stein Z, Nichols A: Family history as an independent risk factor for coronary artery disease. $J \mathrm{Am}$ Coll Cardiol 1984, 4:793-80I.

4. Ciruzzi M, Schargrodsky H, Rozlosnik J, Pramparo P, Delmonte H, Rudich V, Piskorz D, Negri E, Soifer S, La Vecchia C: Frequency of family history of acute myocardial infarction in patients with acute myocardial infarction. Argentine FRICAS (Factores de Riesgo Coronario en America del Sur) Investigators. Am J Cardiol 1997, 80: I22-127.

5. Rissanen AM: Familial occurrence of coronary heart disease: effect of age at diagnosis. Am J Cardiol 1979, 44:60-66.

6. Helgadottir A, Manolescu A, Thorleifsson G, Gretarsdottir S, Jonsdottir H, Thorsteinsdottir U, Samani NJ, Gudmundsson G, Grant SF, Thorgeirsson G, Sveinbjornsdottir S, Valdimarsson EM, Matthiasson SE, Johannsson H, Gudmundsdottir O, Gurney ME, Sainz J, Thorhallsdottir M, Andresdottir M, Frigge ML, Topol EJ, Kong A, Gudnason V, Hakonarson H, Gulcher JR, Stefansson K: The gene encoding 5lipoxygenase activating protein confers risk of myocardial infarction and stroke. Nat Genet 2004, 36:233-239.

7. Helgadottir A, Manolescu A, Helgason A, Thorleifsson G, Thorsteinsdottir U, Gudbjartsson DF, Gretarsdottir S, Magnusson KP, Gudmundsson G, Hicks A, Jonsson T, Grant SF, Sainz J, O'Brien SJ, Sveinbjornsdottir S, Valdimarsson EM, Matthiasson SE, Levey Al, Abramson JL, Reilly MP, Vaccarino V, Wolfe ML, Gudnason V, Quyyumi AA, Topol EJ, Rader DJ, Thorgeirsson G, Gulcher JR, Hakonarson $\mathrm{H}$, Kong $\mathrm{A}$, Stefansson $\mathrm{K}$ : A variant of the gene encoding leukotriene A4 hydrolase confers ethnicity-specific risk of myocardial infarction I. Nat Genet 2006, 38:68-74.

8. Wang Q, Rao S, Shen GQ, Li L, Moliterno DJ, Newby LK, Rogers WJ, Cannata R, Zirzow E, Elston RC, Topol Ej: Premature Myocardial Infarction Novel Susceptibility Locus on Chromosome I P3436 Identified by Genomewide Linkage Analysis. Am J Hum Genet 2004, 74:262-27I.

9. Shen GQ, Li L, Girelli D, Seidelmann SB, Rao S, Fan C, Park JE, Xi Q, Li J, Hu Y, Olivieri O, Marchant K, Barnard J, Corrocher R, Elston R, Cassano J, Henderson S, Hazen SL, Plow EF, Topol EJ, Wang QK: An LRP8 Variant Is Associated with Familial and Premature Coronary Artery Disease and Myocardial Infarction. Am J Hum Genet 2007, 81:780-791.

10. Helgadottir A, Thorleifsson G, Manolescu A, Gretarsdottir S, Blondal $T$, Jonasdottir G, Jonasdottir A, Sigurdsson A, Baker A, Palsson A, Masson G, Gudbjartsson D, Magnusson KP, Andersen K, Levey Al, Backman VM, Matthiasdottir S, Jonsdottir T, Palsson ST, H E, Gunnarsdottir S, Gylfason A, Vaccarino V, Hooper W, Reilly MP, CB G, Austin HA, Rader DJ, SH S, AA A, Gulcher J, Thorgeirsson G, Thorsteinsdottir $U$, Kong A, Stefansson $K$ : A common variant on chromosome 9p2 I affects the risk of myocardial infarction. Science 2007 in press.

II. McPherson R, Pertsemlidis A, Kavaslar N, Stewart A, Roberts R, Cox DR, Hinds DA, Pennacchio LA, Tybjaerg-Hansen A, Folsom AR, Boerwinkle $\mathrm{E}$, Hobbs HH, Cohen JC: A Common Allele on Chromosome 9 Associated with Coronary Heart Disease. Science 2007.

12. Samani NJ, Erdmann J, Hall AS, Hengstenberg C, Mangino M, Mayer B, Dixon RJ, Meitinger T, Braund P, Wichmann HE, Barrett JH, Konig IR, Stevens SE, Szymczak S, Tregouet DA, lles MM, Pahlke F, Pollard $H$, Lieb W, Cambien F, Fischer M, Ouwehand W, Blankenberg S, Balmforth AJ, Baessler A, Ball SG, Strom TM, Braenne I, Gieger C, Deloukas P, Tobin MD, Ziegler A, Thompson JR, Schunkert H: Genomewide association analysis of coronary artery disease. N Engl J Med 2007, 357:443-453.

13. Consortium WTCC: Genome-wide association study of $\mathbf{1 4 , 0 0 0}$ cases of seven common diseases and 3,000 shared controls. Nature 2007, 447:661-678.

14. Broadbent HM, Peden JF, Lorkowski S, Goel A, Ongen H, Green F, Clarke R, Collins R, Franzosi MG, Tognoni G, Seedorf U, Rust S, Eriksson P, Hamsten A, Farrall M, Watkins H: Susceptibility to coronary artery disease and diabetes is encoded by distinct, tightly linked SNPs in the ANRIL locus on chromosome 9p. Hum Mol Genet 2008, I7:806-8I4.

15. Hauser ER, Crossman DC, Granger CB, Haines JL, Jones CJ, Mooser $V$, McAdam B, Winkelmann BR, Wiseman AH, Muhlestein JB, Bartel AG, Dennis CA, Dowdy E, Estabrooks S, Eggleston K, Francis S, Roche K, Clevenger PW, Huang L, Pedersen B, Shah S, Schmidt S, Haynes C, West S, Asper D, Booze M, Sharma S, Sundseth S, Middleton L, Roses AD, Hauser MA, Vance JM, Pericak-Vance MA, Kraus
WE: A genomewide scan for early-onset coronary artery disease in $\mathbf{4 3 8}$ families: the GENECARD Study. Am J Hum Genet 2004, 75:436-447.

16. Dupuis J, Larson MG, Vasan RS, Massaro JM, Wilson PW, Lipinska I, Corey D, Vita JA, Keaney JF Jr., Benjamin EJ: Genome scan of systemic biomarkers of vascular inflammation in the Framingham Heart Study: evidence for susceptibility loci on Iq. Atherosclerosis 2005, 182:307-3|4.

17. Langefeld CD, Wagenknecht LE, Rotter JI, Williams AH, Hokanson JE, Saad MF, Bowden DW, Haffner S, Norris JM, Rich SS, Mitchell BD: Linkage of the metabolic syndrome to Iq23-q3I in Hispanic families: the Insulin Resistance Atherosclerosis Study Family Study. Diabetes 2004, 53:1 I70-II 74

18. Porreca E, DiFebbo C, Reale M, Castellani ML, Baccante G, Barbacane R, Conti P, Cuccurullo F, Poggi A: Monocyte chemotactic protein I (MCP-I) is a mitogen for cultured rat vascular smooth muscle cells. Journal of Vascular Research 1997, 34:58-65.

19. Ford ES: The metabolic syndrome and mortality from cardiovascular disease and all-causes: findings from the National Health and Nutrition Examination Survey II Mortality Study. Atherosclerosis 2004, 173:309-314.

20. Pyorala M, Miettinen H, Halonen P, Laakso M, Pyorala K: Insulin resistance syndrome predicts the risk of coronary heart disease and stroke in healthy middle-aged men - The 22-year follow-up results of the Helsinki Policemen Study. Arteriosclerosis Thrombosis and Vascular Biology 2000, 20:538-544.

21. Fan AZ: Metabolic syndrome and progression of atherosclerosis among middle-aged US adults. Journal of Atherosclerosis and Thrombosis 2006, 13:46-54.

22. Connelly JJ, Wang T, Cox JE, Haynes C, Wang L, Shah SH, Crosslin DR, Hale AB, Nelson S, Crossman DC, Granger CB, Haines JL, Jones C], Vance JM, Goldschmidt-Clermont PJ, Kraus WE, Hauser ER, Gregory SG: GATA2 Is Associated with Familial Early-Onset Coronary Artery Disease. PLoS Genet 2006, 2.

23. Wang L, Hauser ER, Shah SH, Pericak-Vance MA, Haynes C, Crosslin $D$, Harris $M$, Nelson $S$, Hale AB, Granger CB, Haines JL, Jones CJ, Crossman D, Seo D, Gregory SG, Kraus WE, Goldschmidt-Clermont PJ, Vance JM: Peakwide mapping on chromosome 3q 13 identifies the kalirin gene as a novel candidate gene for coronary artery disease. Am J Hum Genet 2007, 80:650-663.

24. Shorts-Cary L, Xu M, Ertel J, Kleinschmidt-DeMasters BK, Lillehei K, Matsuoka I, Nielsen-Preiss S, Wierman ME: Bone morphogenetic protein and retinoic acid-inducible neural specific protein-3 is expressed in gonadotrope cell pituitary adenomas and induces proliferation, migration, and invasion. Endocrinology 2007, I 48:967-975

25. Watkins H, Farrall M: Genetic susceptibility to coronary artery disease: from promise to progress. Nat Rev Genet 2006, 7:163-173.

26. Clarke MCH, Figg N, Maguire J], Davenport AP, Goddard M, Littlewood TD, Bennett MR: Apoptosis of vascular smooth muscle cells induces features of plaque vulnerability in atherosclerosis. Nature Medicine 2006, I 2:1075-1080.

27. Hauser ER, Mooser V, Crossman DC, Haines JL, Jones CH, Winkelmann BR, Schmidt S, Scott WK, Roses AD, Pericak-Vance MA, Granger CB, Kraus WE: Design of the genetics of early onset cardiovascular disease (GENECARD) study. Am Heart J 2003, 145:602-613.

28. Fortin DF, Califf RM, Pryor DB, Mark DB: The way of the future redux. Am J Cardiol 1995, 76: I I77-I I82.

29. Smith LR, Harrell FE, Rankin JS, Califf RM, Pryor DB, Muhlbaier LH, Lee KL, Mark DB, Jones RH, Oldham HN, Glower DD, Reves JG, Sabiston DC: Determinants of Early Versus Late Cardiac Death in Patients Undergoing Coronary-Artery Bypass Graft-Surgery. Circulation 1991, 84:245-253.

30. Kong DF, Shaw LK, Harrell FE, Muhlbaier LH, Lee KL, Califf RM, Jones $\mathrm{RH}$ : Predicting survival from the coronary arteriogram: an experience-based statistical index of coronary artery disease severity. Journal of the American College of Cardiology 2002, 39(Suppl A):327A.

31. Felker GM, Shaw LK, O'Connor CM: A standardized definition of ischemic cardiomyopathy for use in clinical research. J Am Coll Cardiol 2002, 39:2 10-218.

32. Luo AK, Jefferson BK, Garcia MJ, Ginsburg GS, Topol EJ: Challenges in the phenotypic characterisation of patients in genetic 
studies of coronary artery disease. Journal of Medical Genetics 2007, 44: $16 \mid-165$.

33. Seo D, Wang T, Dressman H, Herderick EE, Iversen ES, Dong C, Vata K, Milano CA, Rigat F, Pittman J, Nevins JR, West M, GoldschmidtClermont PJ: Gene Expression Phenotypes of Atherosclerosis. Arterioscler Thromb Vasc Biol 2004, 24:1922-1927.

34. Oliveira S, Li YJ, Noureddine M, Zuchner S, Qin X, Pericak-Vance MA, Vance JM: Identification of risk and age-at-onset genes on chromosome Ip in Parkinson disease. Am J Hum Genet 2005, 77:252-264.

35. Abecasis GR, Cookson WO: GOLD--graphical overview of linkage disequilibrium. Biolnformatics 2000, 16:182-183.

36. Barrett JC, Fry B, Maller J, Daly MJ: Haploview: analysis and visualization of LD and haplotype maps. Biolnformatics 2005, 21:263-265.

37. Cottingham RW Jr., Idury RM, Schaffer AA: Faster sequential genetic linkage computations. Am J Hum Genet 1993, 53:252-263.

38. Schaffer AA, Gupta SK, Shriram K, Cottingham RW: Avoiding recomputation in linkage analysis. Hum Hered 1994, 44:225-237.

39. Ott J: Analysis of Human Genetic Linkage. Third Edition 3rd edition. Baltimore, Maryland, The Johns Hopkins University Press; 1999.

40. Martin ER, Bass MP, Hauser ER, Kaplan NL: Accounting for linkage in family-based tests of association with missing parental genotypes. Am J Hum Genet 2003, 73:1016-1026.

4I. Chung RH, Hauser ER, Martin ER: The APL Test: Extension to General Nuclear Families and Haplotypes and Examination of Its Robustness. Hum Hered 2006, 61:189-199.

42. Martin ER, Monks SA, Warren LL, Kaplan NL: A test for linkage and association in general pedigrees: the pedigree disequilibrium test. Am J Hum Genet 2000, 67: I46-I54.

43. Martin ER, Bass MP, Gilbert JR, Pericak-Vance MA, Hauser ER: Genotype-based association test for general pedigrees: the genotype-PDT. Genet Epidemiol 2003, 25:203-213.

44. Li M, Boehnke M, Abecasis GR: Joint modeling of linkage and association: identifying SNPs responsible for a linkage signal. Am J Hum Genet 2005, 76:934-949.

45. Li M, Boehnke M, Abecasis GR: Efficient study designs for test of genetic association using sibship data and unrelated cases and controls. Am J Hum Genet 2006, 78:778-792.

46. Livak KJ, Schmittgen TD: Analysis of relative gene expression data using real-time quantitative PCR and the 2(-Delta Delta C(T)) Method. Methods 200I, 25:402-408.

47. Wang X, Ria M, Kelmenson PM, Eriksson P, Higgins DC, Samnegard A, Petros C, Rollins J, Bennet AM, Wiman B, De Faire U, Wennberg C, Olsson PG, Ishii N, Sugamura K, Hamsten A, Forsman-Semb K, Lagercrantz J, Paigen B: Positional identification of TNFSF4, encoding $\mathrm{OX} 40$ ligand, as a gene that influences atherosclerosis susceptibility. Nat Genet 2005, 37:365-372.

48. de Bakker PI, Yelensky R, Pe'er I, Gabriel SB, Daly MJ, Altshuler D: Efficiency and power in genetic association studies. Nat Genet 2005, 37: $1217-1223$.

49. Kruglyak L, Nickerson DA: Variation is the spice of life. Nat Genet 2001, 27:234-236.

50. Hayflick L, Moorhead PS: Serial Cultivation of Human Diploid Cell Strains. Experimental Cell Research 1961, 25:585-\&.

5I. Kawano H, Nakatani T, Mori T, Ueno S, Fukaya M, Abe A, Kobayashi M, Toda F, Watanabe M, Matsuoka I: Identification and characterization of novel developmentally regulated neural-specific proteins, BRINP family. Molecular Brain Research 2004, I 25:60-75.

52. McBride HM, Neuspiel M, Wasiak S: Mitochondria: More than just a powerhouse. Current Biology 2006, I6:R55I-R560.

53. Rustin P: Mitochondria, from cell death to proliferation. Nature Genetics 2002, 30:352-353.

54. Larson MG, Atwood LD, Benjamin EJ, Cupples LA, D'Agostino RB, Fox CS, Govindaraju DR, Guo CY, Heard-Costa NL, Hwang SJ, Murabito JM, Newton-Cheh C, O'Donnell CJ, Seshadri S, Vasan RS, Wang T], Wolf PA, Levy D: Framingham Heart Study I00K project: genome-wide associations for cardiovascular disease outcomes. Bmc Medical Genetics 2007, 8:

55. Vasan RS, Larson MG, Aragam J, Wang TJ, Mitchell GF, Kathiresan S, Newton-Cheh C, Vita JA, Keyes MJ, O'Donnell CJ, Levy D, Benjamin E]: Genome-wide association of echocardiographic dimensions, brachial artery endothelial function and treadmill exercise responses in the Framingham Heart Study. Bmc Medical Genetics 2007, 8:.
56. Gustafson B, Hammarstedt A, Andersson CX, Smith U: Inflamed adipose tissue - $A$ culprit underlying the metabolic syndrome and atherosclerosis. Arteriosclerosis Thrombosis and Vascular Biology 2007, 27:2276-2283.

57. Espinola-Klein C, Rupprecht HJ, Bickel C, Post F, Genth-Zotz S, Lackner K, Munzel T, Blankenberg S: Impact of metabolic syndrome on atherosclerotic burden and cardiovascular prognosis. American Journal of Cardiology 2007, 99:1623-1628.

58. Reinhard W, Holmer SR, Fischer M, Gloeckner C, Hubauer $U$, Baessler A, Mayer B, Schunkert H, Riegger GA, Hengstenberg C: Association of the metabolic syndrome with early coronary disease in families with frequent myocardial infarction. Am J Cardiol 2006, 97:964-967.

59. Benjamini $Y$, Hochberg $Y$ : Controlling the false discovery rate: a practical and powerful approach to multiple testing. J $R$ Stat Soc B 1995, 57:289-300.

\section{Pre-publication history}

The pre-publication history for this paper can be accessed here:

http://www.biomedcentral.com/1471-2350/9/33/prepub
Publish with BioMed Central and every scientist can read your work free of charge

"BioMed Central will be the most significant development for disseminating the results of biomedical research in our lifetime. "

Sir Paul Nurse, Cancer Research UK

Your research papers will be:

- available free of charge to the entire biomedical community

- peer reviewed and published immediately upon acceptance

- cited in PubMed and archived on PubMed Central

- yours - you keep the copyright
BioMedcentral 